\title{
Reseña
}

\section{Historias de sicarios en Uruguay: Entrevistas y confesiones*}

\section{Por: Cristian Maneiro**}

* Gustavo Leal

Historias de sicarios en Uruguay:

Entrevistas y confesiones.

Montevideo: Penguin Random

House, 2021, 326 pp.

ISBN: 978-9915-659-51-0

** Licenciado en Sociología (Udelar, 2009), magíster en Sociología (UFPR, 2015) y especialista en Políticas Públicas y Evaluación (CLEAR LAC, 2021). Consultor en evaluación para agencias de las Naciones Unidas (PMA, UNFPA, UNICEF) y organizaciones no gubernamentales (Aldeas Infantiles SOS, Maestral) en materia de protección infantil, seguridad alimentaria, infancia y adolescencia.

$\triangle$ cristianmaneiro22@gmail.com https://orcid.org/0000-0001-

$5297-4745$
¿Qué razones mueven a un individuo para convertirse en sicario? ¿Como se encuentran la oferta y la demanda (en un mercado necesariamente subterráneo)? ¿Cuál es el proceso de toma de decisiones de estas personas? ¿Cuál es su historia de vida? En Historias de sicarios en Uruguay, el sociólogo Gustavo Leal nos plantea estas preguntas disparadoras y busca respuestas a lo largo de una serie de entrevistas con personas involucradas en crímenes de sicariato.

El libro presenta seis casos policiales narrados como historias independientes. En cada uno se hace una breve introducción, una composición de lugar con descripción de las locaciones y los actores involucrados y un desarrollo cronológico de los acontecimientos, para luego pasar a las entrevistas con sicarios materiales e intelectuales, quienes en todos los casos se encuentran alojados en centros de reclusión dentro del territorio nacional.

En la introducción se ahonda en la etimología y el origen histórico del término, remontable hasta el Imperio romano; se clasifican y describen las características del sicariato profesional y amateur, sus modos de reclutamiento, así como las particularidades de los sicarios como individuos proveedores de un servicio que puede ser permanente o puntual, insertarse como parte de una estructura criminal o realizarse de manera autónoma.

La configuración del sicariato como fenómeno criminal implica cuatro actores principales: autor inte- 
lectual, autor material, intermediario y víctima, unidos por vínculos violentos e inestables. Así, muchas veces el autor intelectual puede convertirse en víctima si no paga lo convenido o no cede a las potenciales extorsiones del autor material o un intermediario, pero también el autor material puede ser eliminado por los autores intelectuales como forma de borrar las huellas de su crimen.

A partir de la revisión de antecedentes, se introducen clasificaciones adicionales del sicariato con base en sus motivaciones (emotivo, didáctico y transformativo) y se sitúa la inserción de la modalidad en la economía del crimen. El sicariato es una modalidad que crece regionalmente bajo el influjo del crimen organizado y el narcotráfico, y se presenta como un servicio específico sujeto a las leyes de la oferta y la demanda en el mercado criminal.

Al trazar el perfil de los sicarios, se encuentra en común la forma extremadamente violenta de resolver conflictos basados en la no aceptación de situaciones relativamente cotidianas (o al menos no tan excepcionales como para que no puedan encontrarse otras formas de resolución): rupturas amorosas, reparto desigual de herencias, derrotas deportivas, etcétera. Eso se liga con un distanciamiento ético y moral, la ausencia de sentimientos de culpa y el desprecio por la vida ajena, que el autor, a partir de bibliografía especializada, no duda en calificar como personalidad psicopática.

Entre las principales fortalezas de la obra se destaca su originalidad. Hasta donde sabemos, no existen en Uruguay trabajos que intenten sistematizar historias de vida y describan la construcción de un discurso y una ética de quienes por circunstancias diversas optaron por convertirse en sicarios. Asimismo, al concebirse como una obra de circulación masiva, presenta un lenguaje acorde al público no especializado. Al minimizar la jerga sociológica y las apelaciones a la autoridad mediante citas de autores, la lectura se hace ágil y entretenida.

Sin embargo, como se señala en el prólogo, no es un libro fácil de leer. La crudeza de los relatos de personas como el Fofón, el Caco o Muito Loco movilizan subjetivamente y provocan una sensación inicial de indignación y rechazo, pero también, en una segunda lectura, esos testimonios nos interpelan como sociedad y cuestionan la validez de nuestros mitos fundantes, como la sociedad amortiguadora y la Suiza de América. Se problematiza así la tantas veces ponderada excepcionalidad uruguaya y se muestra que, más tarde o más temprano, a partir de hibridaciones y emulación de los modus operandi, los fenómenos regionales acaban por llegar. En este sentido, Medellín, San Pablo o Ciudad Juárez no están tan lejos como quisiéramos creer.

Por último, el libro tiene el mérito de cuestionar la creencia de que el sicariato está exclusivamente relacionado con el mundo del narcotráfico y el estereotipo del sicario joven, pobre y con problemas de adicciones. Este perfil se verifica mayoritariamente entre los autores materiales, que suelen ser individuos con historias de rupturas familiares, ausencia de las figuras paternas y vínculos truncos e intermitentes con el sistema 
educativo y el mercado laboral. No obstante, al elevar la mira y considerar también a los autores intelectuales, surge una heterogeneidad importante, que incluye a profesionales y otras personas de buena posición económica y cultural.

Quizás una breve presentación de datos referentes a la evolución de los casos de sicariato podría haberse agregado a la introducción para cuantificar el fenómeno, así como para explorar otras hipótesis explicativas (estacionalidad, determinantes geográficos, perfil de víctimas).

Asimismo, se podría haber avanzado en integrar las historias presentadas en una teoría más general de la acción, que incluya disposiciones y condiciones objetivas para el sicariato. Aun a riesgo de adquirir un tono más académico y perder su carácter de lectura masiva, un esfuerzo teórico de este tipo podría haber enriquecido la obra.

En la lectura de las historias presentadas puede rastrearse una variedad de hechos sociales. Entre otros, hay evidencias de corrupción en las esferas policial, judicial y penitenciaria; división desigual del trabajo y los cuidados dentro del hogar; determinaciones, identificaciones y rivalidades territoriales; falta de oportunidades reales para abandonar trayectorias delictivas. Si bien trasciende el objetivo de la obra, a partir de estos emergentes quizás podría haberse ensayado, a modo de epílogo, una aproximación inicial a las causas y consecuencias sociales y políticas del fenómeno.

El leit motiv explícito de la obra, con cierta reminiscencia marxista, es comprender para transformar. Con esta intención, más allá de los debates posibles sobre las políticas de seguridad de las administraciones previas o del accionar del propio Leal como director de Convivencia y Seguridad Ciudadana en dichas administraciones, el presente trabajo logra constituirse como un insumo inicial valioso para echar luz sobre el sicariato, entendido como un fenómeno social complejo que permite y reclama distintas miradas disciplinarias. 